Check for updates

Cite this: Chem. Commun., 2022, 58,2363

Received 19th November 2021, Accepted 17th January 2022

DOI: $10.1039 / \mathrm{d} 1 \mathrm{cc} 06524 \mathrm{f}$

rsc.li/chemcomm

\section{Binding affinity of aniline-substituted dodecaborates to cyclodextrins $\$$}

\author{
Tarek Marei, (D) $\S^{a}$ Mahmoud K. Al-Joumhawy, $\S^{a}$ Mohammad A. Alnajjar, (D) $\S^{a}$ \\ Werner M. Nau, (D) ${ }^{a}$ Khaleel I. Assaf ${ }^{b}$ and Detlef Gabel (D) *a
}

\begin{abstract}
A new set of hybrid guest molecules bearing organic and inorganic residues have been studied for their recognition by cyclodextrins in aqueous solution. The guest molecules consist of nitroanilines linked through their amino group to the dodecahydrido-closododecaborate cluster $\mathrm{B}_{12} \mathrm{H}_{12}{ }^{2-}$, which serves as an anchor group. They show sizable affinity to cyclodextrins, and unexpected photophysical properties, with a very strong and low-energy charge-transfer band. The dodecaborate cluster increases the $\mathrm{p} K_{\mathrm{a}}$ of the anilines by 5.0 to $5.7 \mathrm{pH}$ units, and the deprotonated forms of the $o-$ and $p$-nitroaniline derivatives show strong charge transfer absorption bands in the visible part of the spectrum.
\end{abstract}

Boron cluster chemistry has seen tremendous growth in the last decades with respect to the synthesis of new derivatives and their applications in various research fields, ranging from materials science to medicinal chemistry. ${ }^{1-8}$ The properties of ionic icosahedral boron clusters such as $\mathrm{B}_{12} \mathrm{H}_{12}{ }^{2-}$ are different from those of organic anionic molecules. They are well soluble in water, but their interaction with water is influenced by the distribution of the charges within the entire cluster, and the hydridic character of the $\mathrm{H}$ atoms. ${ }^{9}$ The two effects combine in enabling these compounds to dissolve well in water, yet bind to hydrophobic surfaces. Recently, boron cluster anions have been recognized as strong cavity binders to macrocyclic receptors, in particular cyclodextrins (CDs, Fig. 1a). ${ }^{10-17}$ For example, the binding affinities of closo-dodecaborate anions $\left(\mathrm{B}_{12} \mathrm{X}_{12}{ }^{2-}\right.$, $\mathrm{X}=\mathrm{H}, \mathrm{Cl}, \mathrm{Br}, \mathrm{I})$ exceed those of hydrophobic guest molecules. ${ }^{15}$ The high affinity was traced back to the chaotropic nature of the dodecaborate anions, classifying boron clusters as superchaotropic anions. ${ }^{15,18}$ Through the investigation of

\footnotetext{
${ }^{a}$ Department of Life Sciences and Chemistry, Jacobs University Bremen, Bremen D-28759, Germany. E-mail: d.gabel@jacobs-university.de

${ }^{b}$ Department of Chemistry, Faculty of Science,

Al-Balqa Applied University, Al-Salt 19117, Jordan

$\dagger$ Dedicated to Clara Viñas and Francesc Teixidor on the occasion of their 70th birthdays.

‡ Electronic supplementary information (ESI) available. See DOI: 10.1039/d1cc06524f $\S$ These authors contributed equally to the work.
}

several boron-based clusters, it transpires that dihydrogen bonds, dispersion interactions, and the desolvation of the anionic clusters govern the trend in affinities in aqueous solution. Their high chemical and thermal stability as well as the lack of metabolization in the body add additional incentives to pursue their utilization in both material applications and drugs.

Recently, one of the major problems in connecting boron clusters to atoms such as $\mathrm{C}$ and $\mathrm{N}$ has found new solutions through the use of Pd-catalysed cross-coupling reactions with $\mathrm{B}_{12} \mathrm{H}_{11} \mathrm{I}^{2-} \cdot{ }^{19-21}$ This allows one to study the properties of series of similar compounds where chemical changes are small and well-defined. We had reported the synthesis of a number of aniline derivatives, where the dodecaborate cluster is linked directly to the aniline nitrogen; ${ }^{21}$ we had used a BuchwaldHartwig type reaction with iodododecaborate, for which an improved synthesis method had been found. ${ }^{22}$ With this tool,

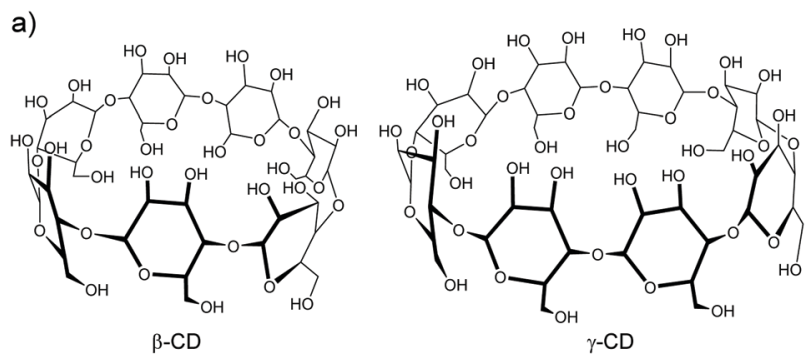

b)
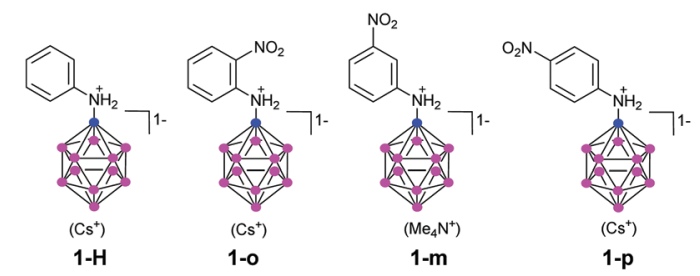

Fig. 1 Molecular structure of cyclodextrins (CDs), the parent anilinesubstituted dodecaborate $(\mathbf{1}-\mathrm{H})$, and its nitroaniline derivatives $\left(\mathrm{O}^{-}, \mathrm{m}-\right.$, $p-$, designated as 1-o, 1-m, and 1-p). 
it is now possible to explore properties and potential applications of such inorganic-organic hybrid molecules.

We picked the three nitroaniline derivatives of dodecaborate $\left(o^{-}, m^{-}, p^{-}\right.$, designated as 1-o, 1-m, and 1-p, respectively, Fig. 1b) the synthesis of which has been described by us before, ${ }^{21}$ together with the parent aniline derivative $\mathbf{1 - H}$, and investigated the influence of the boron cluster on the HOMO-LUMO gap (as estimated by UV-Visible spectroscopy), the $\mathrm{p} K_{\mathrm{a}}$ values of the aniline $\mathrm{N}$ atom, and the binding to CDs of different sizes. We hoped to gain insight into how binding and physicalchemical properties of the derivatives vary with respect to their structure. The nitro group as electron acceptor and the unprotonated aminododecaborate as electron donor should result in a strong push-pull effect, with a considerable red shift of the absorption bands. This shift should disappear when the amine becomes protonated, or when the acceptor is absent. In addition, due to lack of $\pi$ conjugation between the substituents, a nitro group in the meta position with respect to the amine substituent should display a relatively smaller influence on the HOMO-LUMO gap.

For these experiments, water-soluble salts are required. We could precipitate the Cs salts of the nitroaniline derivatives by dissolving the cross-coupling mixture ${ }^{21}$ in methanol after evaporation of DMSO and adding a methanolic solution of CsF. The product precipitated, and was found to be of high purity without requiring chromatography. Solely for the parent aniline derivative 1-H column chromatography was necessary to remove other dodecaborate by-products.

The $\mathrm{p} K_{\mathrm{a}}$ values of nitroanilines are known to be much lower than those of the parent (unsubstituted) aniline (Table 1). The $\mathrm{p} K_{\mathrm{a}}$ values for the nitroaniline boron clusters and the nonnitrated derivative are, however, much higher, by about 5 units (1-o: 5.4, 1-m: 7.8, 1-p: 6.1, 1-H: 9.9), than those of the corresponding free anilines $(-0.3,2.5,1.0$, and 4.9 , see Table 1). The considerable increase in basicity of the $N$ atom reflects the high electron-donating power and the charge of the cluster, strongly favoring the protonated form. Of interest is the observation that the $m$-nitroaniline derivative (1-m) has a $\mathrm{p} K_{\mathrm{a}}$ value close to physiological $\mathrm{pH}$, and the $\mathrm{p} K_{\mathrm{a}}$ of $\mathbf{1 - H}$ is comparable to that of aliphatic amines. Such knowledge will be of importance when drugs would be constructed with such substituents. In terms of the Hammett and Pytela constants $\sigma_{\mathrm{p}}$ and $\sigma^{\mathrm{i}}$, often used to describe the electronic influence on aromatic

Table $1 \mathrm{p} K_{\mathrm{a}}$ values of aniline dodecaborate derivatives in the absence and presence of CDs; measured by following the UV-Vis absorption changes as a function of $\mathrm{pH}$, see $\mathrm{ESI}$

\begin{tabular}{|c|c|c|c|c|}
\hline & 1-H & 1-o & 1-m & 1-p \\
\hline Parent aniline $^{a}$ & 4.9 & -0.3 & 2.5 & 1.0 \\
\hline Boron-substituted aniline & 9.9 & 5.4 & 7.8 & 6.1 \\
\hline$\Delta \mathrm{p} K_{\mathrm{a}}{ }^{b}$ & 5.0 & 5.7 & 5.3 & 5. \\
\hline Complexed with $\beta-\mathrm{CD}^{c}$ & $\mathrm{nd}^{d}$ & 4.4 & 7.2 & 4. \\
\hline Complexed with $\gamma-\mathrm{CD}^{c}$ & $\mathrm{nd}^{d}$ & 5.4 & 8.7 & 5.6 \\
\hline
\end{tabular}

${ }^{a}$ From ref. $24^{b}$ Error in data is ca. 20\%. ${ }^{c}$ Excess CD was added to ensure a high degree of complexation $(>90 \%){ }^{d}$ nd: No reliable determination possible, see note. ${ }^{25}$ systems, the $\mathrm{N}$-dodecaborate derivatives are much stronger electron donors than any of the commonly used substituents. This is borne out also in $\mathrm{N}$-dodecaborate amides described previously, $^{23}$ where the benzamide was isolated in its protonated form.

In the spectra of the non-protonated forms of 1-o, 1-m, and 1-p (see Fig. 2), we found charge-transfer (CT) absorption bands which were much more red-shifted than those described for $m$ and $p$-nitroaniline. ${ }^{26}$ Thus, for $p$-nitroaniline in water, the maximum absorption due to the CT band is around $360 \mathrm{~nm}$, whereas the dodecaborate analogue 1-p has its maximum at $450 \mathrm{~nm}$. The change in the CT band corresponds to the high electron-donating power of dodecaborate, which is empirically known from its chemical reactions. There is no influence of the protonation state on the CT band of $\mathbf{1 - H}$, and its longwavelength absorbance at $290 \mathrm{~nm}$ stays constant with $\mathrm{pH}$. For 1-m, as expected, we found a greatly reduced CT band in comparison to 1-o and 1-p, due to lack of resonance effects in this position.

We knew from previous experiments that monosubstituted boron clusters can bind more strongly to CDs than the nonsubstituted parent clusters. ${ }^{14}$ Therefore, we expected the nitroaniline derivatives to show a higher affinity than $\mathrm{B}_{12} \mathrm{H}_{12}{ }^{2-}$. With structurally related substituents, we hoped to see how much the physical-chemical properties and the binding affinity to CDs of different sizes could be related to the substitution pattern.

At high $\mathrm{pH}$, i.e., when the guests are in their deprotonated forms, the nitroaniline derivatives bind well, with millimolar or higher affinities, to both $\beta$-CD and $\gamma$-CD (see Table 2). ${ }^{25}$ Guest molecules undergo a complexation-induced $\mathrm{p} K_{\mathrm{a}}$ shift upon complexation by CDs, and this results generally in a decrease of the $\mathrm{p} K_{\mathrm{a}}$ values of ammonium ions/amines in their CDcomplexed states. ${ }^{27-29}$ The underlying reason is that CDs tend to bind hydrophobic neutral amines more strongly in their hydrophobic cavity. ${ }^{30}$ For $\beta$-CD complexation of the nitroaniline derivatives, the shift is in the expected direction $\left(\mathrm{p} K_{\mathrm{a}}\right.$ values

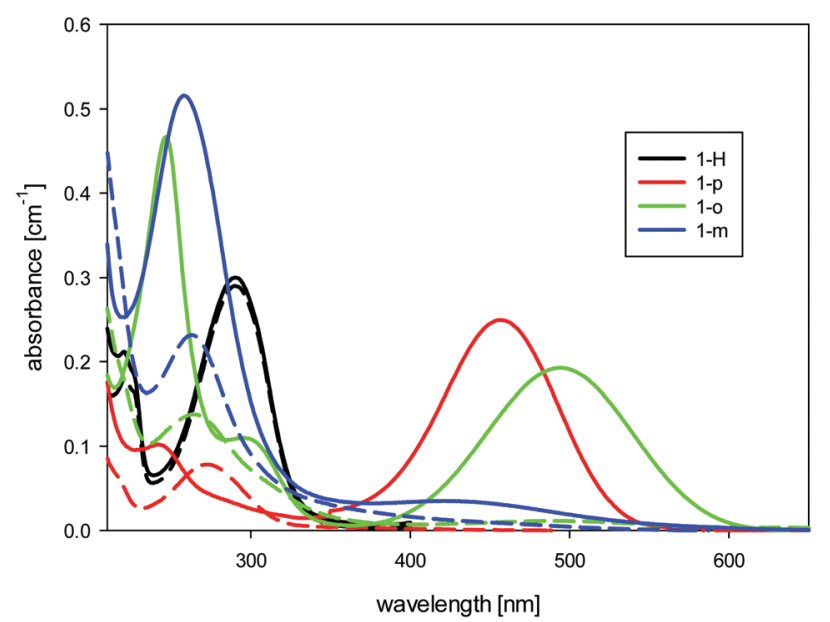

Fig. 2 UV-Visible absorption spectra of the dodecaborate-substituted anilines in water (concentration $10 \mu \mathrm{M}$ ) at high (solid line) and low (dashed line) $\mathrm{pH}$ values. 
Table 2 Association constants ( $K_{\text {ass }}$ ) and thermodynamic data (in $\mathrm{kcal} \mathrm{mol}^{-1}$ ) for the complexation of the parent $\mathrm{B}_{12} \mathrm{H}_{12}{ }^{2-}$ and aniline-substituted dodecaborates and CDs in water as measured by isothermal titration calorimetry, ITC, see ESI

\begin{tabular}{llllll}
\hline Derivative & $\mathrm{CD}$ & $K_{\text {ass }}{ }^{a} / 10^{3} \mathrm{M}^{-1}$ & $-\Delta H^{b}$ & $T \Delta S^{b}$ & $-\Delta G^{b}$ \\
\hline $\mathbf{B}_{\mathbf{1 2}} \mathbf{H}_{\mathbf{1 2}}{ }^{2-}$ & $\beta^{c}$ & 0.2 & & & \\
\multirow{2}{*}{ 1-H } & $\gamma^{c}$ & 2.0 & & & \\
& $\beta$ & $\mathrm{nd}^{d}(31 \pm 6)$ & $(11 \pm 3)$ & $(5.0)$ & $(6.0)$ \\
$\mathbf{1 - 0}$ & $\gamma$ & $\mathrm{nd}^{d}(5.9 \pm 3.4)$ & $(7.5 \pm 0.7)$ & $(2.4)$ & $(5.1)$ \\
& $\beta$ & $5.7 \pm 2.0(0.6)$ & $1.2 \pm 0.7$ & 3.9 & 5.1 \\
1-m & $\gamma$ & $15 \pm 4(15)$ & $2.9 \pm 0.1$ & 2.9 & 5.8 \\
& $\beta$ & $18 \pm 6(4.5)$ & $2.8 \pm 0.1$ & 3.0 & 5.8 \\
1-p & $\gamma$ & $9.6 \pm 3.6(76)$ & $1.2 \pm 0.1$ & 4.2 & 5.4 \\
& $\beta$ & $19 \pm 5(1.0)$ & $2.0 \pm 0.3$ & 3.8 & 5.8 \\
& $\gamma$ & $7.6 \pm 0.7(2.4)$ & $4.3 \pm 0.6$ & 1.0 & 5.3
\end{tabular}

${ }^{a}$ Values without parentheses pertain to the deprotonated form (determined by ITC at $\mathrm{pH} 9$ ), values in parentheses to the protonated form (extrapolated from the $\mathrm{p} K_{\mathrm{a}}$ shifts in Table 1 for 1-o, 1-m, and 1-p, and determined by ITC at pH 3 for 1-H). ${ }^{b}$ All in kcal mol ${ }^{-1}, T=298 \mathrm{~K} .{ }^{c}$ By NMR, from ref. $15^{d}$ nd: No reliable determination possible, see note. ${ }^{25}$

lower than the uncomplexed compounds) (Table 1), with the deprotonated form as the favored form for binding. As the net charge is decreased by deprotonation (from -1 to -2 ), a higher $\mathrm{p} K_{\mathrm{a}}$ would have been expected if the net charge was the dominant driving force in complexation. As, however, a pronounced hydration of the positively charged $N$ atoms has been found in molecular dynamics simulations, ${ }^{9}$ binding to $\beta-\mathrm{CD}$ would require ammonium-solvating water to be removed, with an energetic penalty. Upon complexation with $\gamma-\mathrm{CD}$, the $\mathrm{p} K_{\mathrm{a}}$ values for 1-o and 1-p are influenced less than for 1-m; for the latter, an increase (rather than an expected decrease) of $0.9 \mathrm{pH}$ units is found.

As we knew the $\mathrm{p} K_{\mathrm{a}}$ values of both the free and bound dodecaborate anilines (Table 1), and since the binding constants of the unprotonated forms could be directly measured by isothermal titration calorimetry (ITC, Table S2 and ESI $\ddagger$ ), one can estimate the association constants of the protonated forms through the known thermodynamic cycle. These binding constants are also found in Table 2 (values in parentheses). Binding to $\beta$-CD is stronger than binding to $\gamma$-CD for equivalent protonation states. For $\gamma-\mathrm{CD}, K_{\text {ass }}$ does not show a clear dependence between the two protonation states.

While being unprotonated, in their dianionic forms, the three nitroaniline derivatives bind quite strongly $\left(K_{\text {ass }}\right.$ around $10^{4} \mathrm{M}^{-1}$ ) to $\gamma$-CD, more strongly than the unsubstituted parent cluster. Binding to $\beta$-CD of all derivatives in both protonation states investigated here is stronger than the binding of the parent $\mathrm{B}_{12} \mathrm{H}_{12}{ }^{2-} .{ }^{25}$ For $\mathrm{B}_{12} \mathrm{H}_{12}{ }^{2-}$ and $\beta-\mathrm{CD}$, we had found an association constant of only $2 \times 10^{2} \mathrm{M}^{-1}$. ${ }^{15}$ The binding of $\mathrm{B}_{12} \mathrm{H}_{12}{ }^{2-}$ to $\gamma$-CD is one order of magnitude stronger $(2.0 \times$ $10^{3} \mathrm{M}^{-1}$ ). This demonstrates that monosubstitution has a synergetic effect on the binding. Binding is driven about equally by enthalpic and entropic contributions, which suggests an interplay between chaotropic cluster binding (enthalpically favorable) and hydrophobic binding (entropically driven). ${ }^{18}$ The enthalpy-entropy compensation which we had observed before for other derivatives ${ }^{15}$ is also found for the compounds investigated here (thermodynamic data from ITC in Table 2).

In the UV/Vis spectra, the binding of the different derivatives to both CDs leads only to small bathochromic shifts. This is in contrast to one of the two dodecaborate-substituted nitrobenzodiazoles described earlier, ${ }^{14}$ where larger shifts were found. In the case of the anilines, the shifts were too small to be used for a reliable determination of the association constants by UV/ Vis titrations, such that the ITC affinity data could not be readily verified by an independent technique. However, the complexation of the nitroaniline derivatives could be further structurally verified by using NMR spectroscopy (Fig. 3). The formation of host-guest inclusion complexes could be monitored through the complexation-induced chemical shifts, and in particular for the signals of the CD hosts. ${ }^{14,15}$ For example, the complexation of 1-m with $\beta$-CD resulted in an up-field shift of $\mathrm{H} 1$ and $\mathrm{H} 2$, as well as a down-field shift of the $\mathrm{H} 3$ proton, which is located inside the cavity. The resonances of the aromatic protons of the anilines also experienced shifts upon complexation. Similar effects were observed for the complexation of 1-p with $\beta$-CD. For $\gamma$-CD, very pronounced shifts were observed for the complexation of 1-m and 1-p (Fig. 3), which might indicate that the guest protrudes more deeply into the larger cavity of $\gamma$-CD. Overall, the ${ }^{1} \mathrm{H}$ NMR experiments suggest that the complexation of the nitroaniline derivatives occurs through the boron cluster, as also anticipated from our previous study. ${ }^{13-15}$ To further support this conclusion, 2D-ROESY experiments (see ESI $\$$ ) were conducted, which did not reveal any cross-peaks between the aromatic protons of the anilines and the CD protons (see Fig. 4 for modelled structures). Furthermore, theoretical calculations indicated that the inclusion complexation between the CDs and the inorganic cluster is preferred over that for the organic part (Fig. 4).

In conclusion, we have found that the aniline-substituted dodecaborates are more basic than the parent anilines, with $\mathrm{p} K_{\mathrm{a}}$ values shifting such that $N$-protonation under physiological $\mathrm{pH}$ values must be considered. In comparison to nonboronated anilines, the charge-transfer bands of the orthoand para-substituted derivatives are shifted to considerably

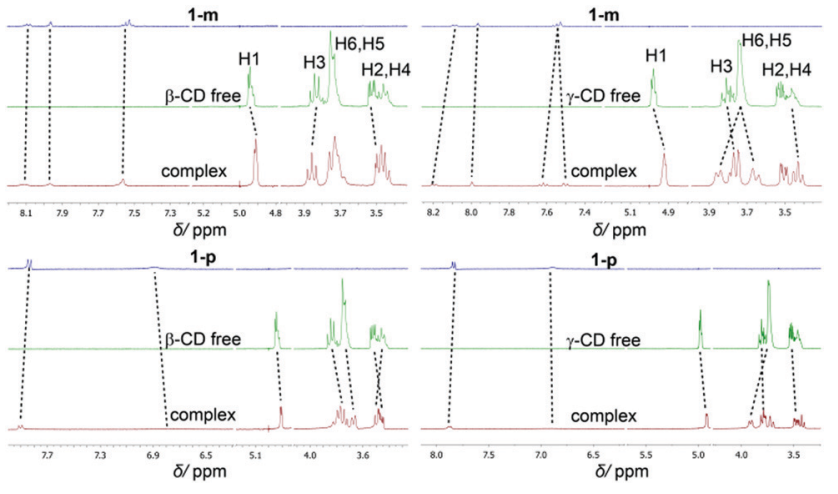

Fig. 3 Shifts of ${ }^{1} \mathrm{H}-\mathrm{NMR}$ resonances upon binding of 1-m (top) and 1-p (bottom) to $\beta$-(left) and $\gamma$-CD (right). 


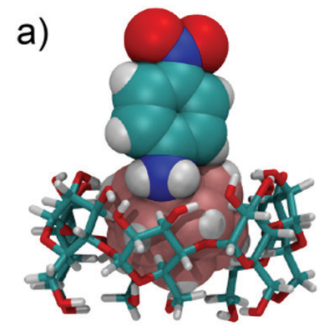

b)

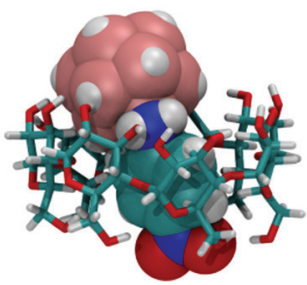

Fig. 4 Binding of $\mathbf{1 - p}$, in its protonated state, to $\beta$-CD. (a) "inorganic head-first"; (b) "organic feet-first"; structures were optimized by using the semi-empirical method PM3.

longer visible wavelengths. The compounds complex strongly ( $\mathrm{mM}$ and higher affinities) with both $\beta$ - and $\gamma$-CD.

The authors are grateful to the DFG for grants GA 250/55-1, NA 686/15-1, and NA 686/8-2.

\section{Conflicts of interest}

There are no conflicts to declare.

\section{Notes and references}

1 E. Justus, K. Rischka, J. F. Wishart, K. Werner and D. Gabel, Chem. Eur. J., 2008, 14, 1918-1923.

2 T. Kondo, Sci. Technol. Adv. Mater., 2017, 18, 780-804.

3 E. Hey-Hawkins and C. Viñas, Teixidor, boron-based compounds: potential and emerging applications in medicine, John Wiley \& Sons, 2018.

4 B. P. Dash, R. Satapathy, J. A. Maguire and N. S. Hosmane, New J. Chem., 2011, 35, 1955-1972.

5 D. Gabel, Pure Appl. Chem., 2015, 87, 173-179.

6 P. Řezáčová, J. Pokorná, J. Brynda, M. Kožíšek, P. Cígler, M. Lepšík, J. Fanfrlík, J. Rezáč, K. Grantz Šašková, I. Sieglová, J. Plešek, V. Šícha, B. Grüner, H. Oberwinkler, J. Sedláček', H.-G. Kräusslich, P. Hobza, V. Král and J. Konvalinka, J. Med. Chem., 2009, 52, 7132-7141.

7 L. He, H.-W. Li, H. Nakajima, N. Tumanov, Y. Filinchuk, S.-J. Hwang, M. Sharma, H. Hagemann and E. Akiba, Chem. Mater., 2015, 27, 5483-5486.

8 Y. Zhang, L. Yang, L. Wang, S. Duttwyler and H. Xing, Angew. Chem., Int. Ed., 2019, 58, 8145-8150.
9 K. Karki, D. Gabel and D. Roccatano, Inorg. Chem., 2012, 51, 4894-4896.

10 S. El Anwar, K. I. Assaf, B. Begaj, M. A. Samsonov, Z. Růžičková, J. Holub, D. Bavol, W. M. Nau, D. Gabel and B. Grüner, Chem. Commun., 2019, 55, 13669-13672.

11 K. I. Assaf, B. Begaj, A. Frank, M. Nilam, A. S. Mougharbel, U. Kortz, J. Nekvinda, B. Grüner, D. Gabel and W. M. Nau, J. Org. Chem., 2019, 84, 11790-11798.

12 K. I. Assaf, A. Hennig, S. Peng, D.-S. Guo, D. Gabel and W. M. Nau, Chem. Commun., 2017, 53, 4616-4619.

13 K. I. Assaf, D. Gabel, W. Zimmermann and W. M. Nau, Org. Biomol. Chem., 2016, 14, 7702-7706.

14 K. I. Assaf, O. Suckova, N. Al Danaf, V. von Glasenapp, D. Gabel and W. M. Nau, Org. Lett., 2016, 18, 932-935.

15 K. I. Assaf, M. S. Ural, F. Pan, T. Georgiev, S. Simova, K. Rissanen, D. Gabel and W. M. Nau, Angew. Chem., Int. Ed., 2015, 54, 6852-6856.

16 K. I. Assaf, J. Holub, E. Bernhardt, J. M. Oliva-Enrich, M. I. Fernández Pérez, M. Canle, J. A. Santaballa, J. Fanfrlík, D. Hnyk and W. M. Nau, ChemPhysChem, 2020, 21, 971-976.

17 S. M. Eyrilmez, E. Bernhardt, J. Z. Dávalos, M. Lepšík, P. Hobza, K. I. Assaf, W. M. Nau, J. Holub, J. M. Oliva-Enrich, J. Fanfrlík and D. Hnyk, Phys. Chem. Chem. Phys., 2017, 19, 11748-11752.

18 K. I. Assaf and W. M. Nau, Angew. Chem., Int. Ed., 2018, 57, 13968-13981.

19 T. Peymann, C. B. Knobler and M. F. Hawthorne, Inorg. Chem., 1998, 37, 1544-1548.

20 A. Himmelspach, M. Finze, A. Vöge and D. Gabel, Z. Anorg. Allg. Chem., 2012, 638, 512-519.

21 M. K. Al-Joumhawy, T. Marei, A. Shmalko, P. Cendoya, J. La Borde and D. Gabel, Chem. Commun., 2021, 57, 10007-10010.

22 M. Al-Joumhawy, P. Cendoya, A. Shmalko, T. Marei and D. Gabel, J. Organomet. Chem., 2021, 949, 121967.

23 S. Hoffmann, E. Justus, M. Ratajski, E. Lork and D. Gabel, J. Organomet. Chem., 2005, 690, 2757-2760.

24 CRC Handbook of Chemistry and Physics, ed. J. R. Rumble, CRC Press, 101 st edn, 2020.

25 For 1-H, because of its high pKa value of 9.9, partial deprotonation of CDs, particularly $\beta$-CD (ref. 30), and the possible interplay between deprotonation of CDs and 1-H might make the measured values less certain, such that we omit them from the discussion.

26 F. Bureš, $R S C A d v$., 2014, 4, 58826-58851.

27 I. Ghosh and W. M. Nau, Adv. Drug Delivery Rev., 2012, 64, 764-783.

28 A. I. Lazar, J. Rohacova and W. M. Nau, J. Phys. Chem. B, 2017, 121, 11390-11398.

29 J. Mohanty, A. C. Bhasikuttan, W. M. Nau and H. Pal, J. Phys. Chem. $B, 2006,110,5132-5138$.

30 X. Zhang, G. Gramlich, X. Wang and W. M. Nau, J. Am. Chem. Soc., 2002, 124, 254-263. 